\title{
The annual cycle of surface eddy kinetic energy and its influence on eddy momentum fluxes as inferred from altimeter data
}

\section{Xiaoming Zhai}

Centre for Ocean and Atmospheric Sciences, School of Environmental Sciences, University of East Anglia, Norwich, UK

\begin{abstract}
The annual cycle of surface eddy kinetic energy (EKE) and its influence on eddy momentum fluxes are investigated using an updated record of satellite altimeter data. It is found that there is a phase difference between the annual cycles of EKE in the western boundary current regions and EKE in the interior of the subtropical gyres, suggesting that different mechanisms may be at work in different parts of the subtropical gyres. The annual cycles of EKE averaged in the two hemispheres are found to be of similar magnitude but in opposite phase. As a result, the globally-averaged EKE shows little seasonal variability. The longer record of altimeter data used in this study has brought out a clearer and simpler picture of eddy momentum fluxes in the Gulf Stream and Kuroshio Extensions: eddies in both regions systematically flux westerly momentum into the western boundary current jets. Considerable seasonal variations in eddy momentum fluxes are found in the western boundary current regions, which potentially play an important role in modulating the strength of the western boundary currents and their associated recirculation gyres on the seasonal time scale.
\end{abstract}

Keywords: Eddy kinetic energy; eddy momentum flux; seasonal cycle; western boundary current; altimeter

*Correspondence to: Xiaoming Zhai, Centre for Ocean and Atmospheric Sciences, School of Environmental Sciences, University of East Anglia, Norwich, NR4 7TJ, UK; Email: xiaoming.zhai@uea.ac.uk

Received: August 25, 2017; Accepted: October 12, 2017; Published Online: October 19, 2017

Citation: Zhai X. (2017). The annual cycle of surface eddy kinetic energy and its influence on eddy momentum fluxes as inferred from altimeter data. Satellite Oceanography and Meteorology, 2(2): 299. http://dx.doi.org/10.18063/SOM.v2i2.299

\section{Introduction}

$\mathrm{E}$ ddies play an important role in shaping the large-scale ocean circulation and in transporting climatically-relevant tracers such as heat, salt and nutrient in the ocean (e.g. Zhai et al., 2004; Hecht et al., 2008; Greatbatch et al., 2010b). The strength of the eddy activity, often measured by the energy carried by the eddies, varies on a variety of time scales ranging from seasonal to decadal (e.g. Stammer and Wunsch, 1999; Qiu, 1999; Penduff et al., 2004; Zhai et al., 2008; Zhai and Wunsch, 2013; Rieck et al., 2015), as a result of both forced and intrinsic variability (Wilson et al., 2015).

On the seasonal time scale, Qiu (1999) found that the North Pacific Subtropical Countercurrent (STCC) is subject to strong baroclinic instability in spring, but is only weakly unstable in autumn, owing to seasonal variations of the background stratification. As a result, eddy kinetic energy (EKE) associated with the STCC has a maximum in April/May and a minimum in December/
January. On the other hand, Zhai et al. (2008) found that surface EKE in the Gulf Stream region peaks in summer, although the local ocean stratification appears to be most baroclinically unstable (as measured by the Eady growth rate (Eady, 1949)) in late winter. They further found that EKE in all the subtropical gyres in both hemispheres peaks in respective hemispheric summers. Zhai et al. (2008) attributed the greater magnitude of EKE in summer to weaker eddy energy damping arising from the thermal capping of the eddies during summer, whereas during winter the eddies are much more exposed and more strongly damped via thermal interactions with the atmosphere (Zhai and Greatbatch, 2006a,b). The mechanical damping of the eddies by the relative wind effect (Duhaut and Straub, 2006; Zhai and Greatbatch, 2007; Xu et al., 2016) may also have contributed to the observed EKE annual cycle, since the relative wind damping effect depends on the wind speed, which tends to be stronger during the winter season. More recently, Rieck et al. (2015) investigated the annual cycle of surface EKE using a global eddy-

The annual cycle of surface eddy kinetic energy and its influence on eddy momentum fluxes as inferred from altimeter data. C 2017 Xiaoming Zhai. This is an Open Access article distributed under the terms of the Creative Commons Attribution-NonCommercial 4.0 International License (http:// creativecommons.org/licenses/by-nc/4.0/), permitting all non-commercial use, distribution, and reproduction in any medium, provided the original work is properly cited. 
permitting ocean model. They also found that EKE peaks in summer in all subtropical gyres of the Pacific and Atlantic, and suggested thermal interactions with the atmosphere to be the most likely cause of the summer maximum of surface EKE. The mechanism(s) by which the ocean eddy energy is modulated seasonally is still an open question. It also remains unclear whether the seasonal variations of EKE have any dynamical impact, for example, on eddy-mean flow interactions.

In this paper, we revisit the annual cycle of surface EKE using an updated record of satellite altimeter data and highlight a few features that have not been made explicit in the previous studies. We also investigate for the first time the impact of the annual cycle of surface EKE on eddy momentum fluxes, primarily in the western boundary current regions.

\section{Data and Method}

The daily sea surface height (SSH) anomalies produced and distributed by the Copernicus Marine and Environment Monitoring Service (CMEMS) (http:// www.marine.copernicus.eu) are used in this study for the period from 1 January 1993 to 31 December 2016. This SSH anomaly product merges the Ocean Topography Experiment (TOPEX)/Poseidon, Jason-1, ERS-1/2 and Envisat altimetry measurements onto a $0.25^{\circ} \times 0.25^{\circ}$ grid and has been widely used for studying mesoscale variability in the ocean (e.g. Ducet and Le Traon, 2001; Zhai et al., 2008; Rieck et al., 2015; Xu et al., 2016). More detailed information about the altimeter data including error analysis can be found in Ducet and Le Traon (2001). Here we first compute the zonal $\left(u^{\prime}\right)$ and meridional $(v)$ components of surface geostrophic velocity anomalies from the daily SSH anomalies via geostrophy (Ducet and Le Traon, 2001), and then use them to calculate the surface EKE $\left(\frac{u^{\prime 2}+v^{\prime 2}}{2}\right)$ and eddy momentum flux $\left(u^{\prime} v^{\prime}\right)^{1}$. The annual cycles of EKE and eddy momentum flux are obtained by taking their mean values of each calendar month over all 24 years of our study period, respectively. In this study, we define January, February and March to be winter months; April, May and June to be spring months; July, August and September to be summer months; and October, November and December to be autumn months. As will be seen later, this definition of seasons is motivated by the observed annual cycle of surface EKE.

\section{Results}

\subsection{EKE}

EKE averaged over the period of 1993-2016 is characterized by large values in the western boundary current regions and in the Southern Ocean and by moderate and low values in the eastern part and the interior of the ocean basins (Figure 1), consistent with a number of previous studies (e.g. Stammer and Wunsch, 1999; Zhai et al., 2008; Rieck et al., 2015). The spatial patterns of EKE in all four seasons are very similar to that of the annual mean (not shown).

The seasonal EKE anomalies (with respect to the annual mean) exhibit striking coherent large-scale patterns, with the annual cycles of EKE in the two hemispheres appearing to be in opposite phase to each other (Figure 2). Starting from its seasonal minimum

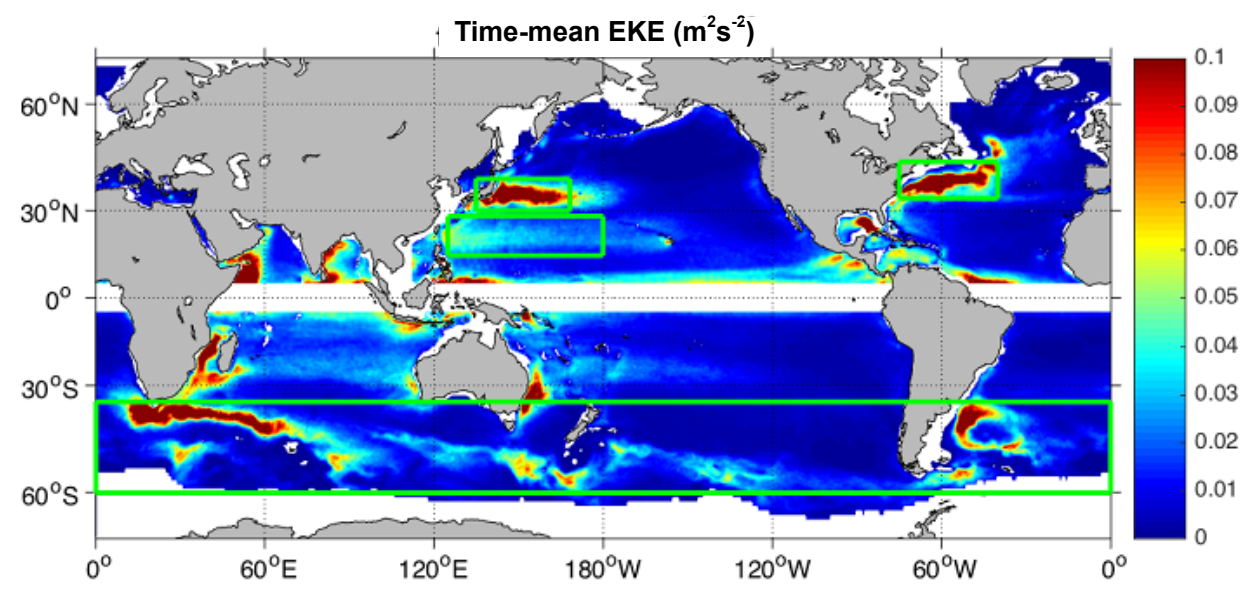

Figure 1. Time-mean EKE over the period of 1993-2016. Regions within $5^{\circ}$ of the equator and regions shallower than $300 \mathrm{~m}$ are excluded in the calculation. The four green rectangular boxes mark the Gulf Stream region $\left(\left[75^{\circ}-40^{\circ} \mathrm{W}, 34^{\circ}-45^{\circ} \mathrm{N}\right]\right)$, the Kuroshio Extension region $\left(\left[135^{\circ}-168^{\circ} \mathrm{E}, 30^{\circ}-40^{\circ} \mathrm{N}\right]\right)$, the interior of the North Pacific $\left(\left[125^{\circ}-180^{\circ} \mathrm{E}, 15^{\circ}-28^{\circ} \mathrm{N}\right]\right)$ and the Southern Ocean $\left(\left[35^{\circ}-60^{\circ} \mathrm{S}\right]\right)$.

\footnotetext{
The other two eddy momentum flux terms, $u^{\prime} u^{\prime}$ and $v^{\prime} v^{\prime}$, although not negligible when considering the local momentum balance, make no contribution to the eddy momentum forcing of the zonal-mean zonal flow.
} 

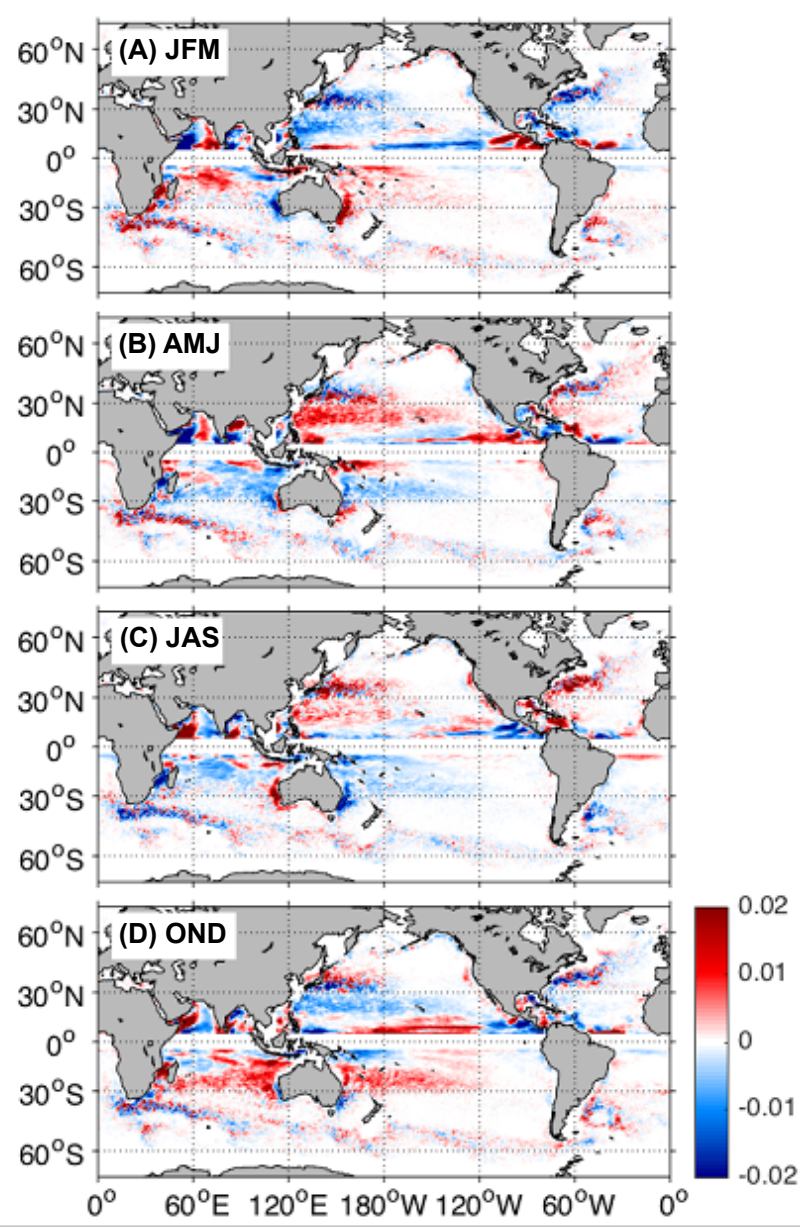

Figure 2. Seasonal EKE anomalies $\left(\mathrm{m}^{2} \mathrm{~s}^{-2}\right)$ in (A) winter, (B) spring, (C) summer and (D) autumn.

in boreal winter, EKE in both the subtropical North Pacific and North Atlantic, including the Kuroshio Extension and Gulf Stream, gradually increases as the year progresses. EKE in the interior of the subtropical gyres reaches its maximum first (in boreal spring), which is followed a few months later (in boreal summer) by EKE in the western boundary current regions. After that, EKE in the subtropical North Pacific and North Atlantic gradually decreases towards its winter minimum. The seasonal evolution of EKE in the Southern Hemisphere ( $\mathrm{SH})$ is generally in opposite phase to that in the Northern Hemisphere $(\mathrm{NH})$, with positive EKE anomalies in austral spring/summer and negative anomalies in austral autumn/winter. One exception is the EKE off the west coast of Australia, which appears to be out of phase with EKE off the east coast and also EKE in other western boundary current regions in the SH.

Figure 3a shows the annual cycles of EKE averaged in the Kuroshio Extension, the Gulf Stream, the interior of the North Pacific and the Southern Ocean. EKE in both western boundary current regions reaches its maximum in August (25\%-30\% greater than its winter minimum), whereas EKE in the interior of the $\mathrm{NH}$ subtropical gyres peaks in May/June ( $~ 80 \%$ greater than its winter minimum), i.e., 2 to 3 months earlier. This phase difference between the interior of the subtropical gyres and western boundary current regions suggests that different mechanisms may be at work in maintaining the annual cycles of EKE in different parts of the subtropical gyres (Qiu, 1999; Zhai et al., 2008). Therefore, the previous statement of EKE in the subtropical gyres peaks in respective hemispheric summers is not entirely accurate (Zhai et al., 2008; Rieck et al., 2015). One subtlety revealed by Figure 2 is that there appears to be a phase difference between the annual cycles of EKE on the southern and northern flanks of the Kuroshio Current (Rieck et al., 2015). The reason for this phase difference across the Kuroshio Current is not clear and requires further investigation in the future. In contrast, the amplitude of the EKE annual cycle in the Southern Ocean is very small (Figure $3 a$ ).

Averaged over each hemisphere (poleward of $5^{\circ}$ in latitude), $\mathrm{EKE}$ in the $\mathrm{NH}$ and $\mathrm{SH}$ peaks in respective hemispheric summers (Figure 3b). The summer maximums of EKE in the $\mathrm{NH}$ and $\mathrm{SH}$ are about $20 \%$ and $15 \%$ greater, respectively, than their winter minimums. As
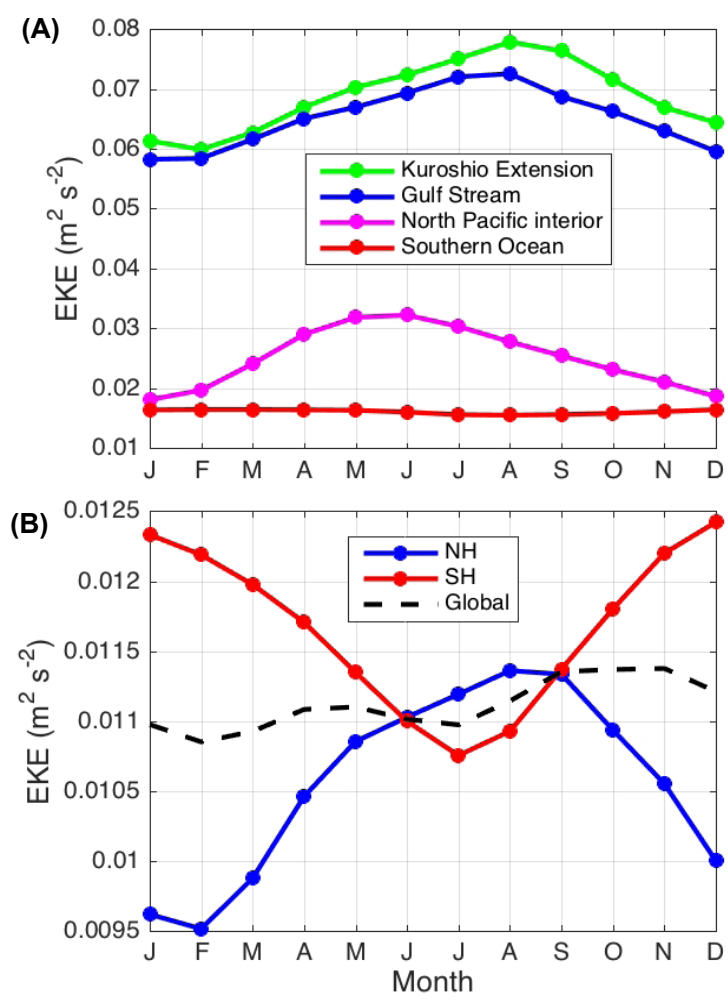

Figure 3. Annual cycles of EKE averaged in (A) the Kuroshio Extension region, the Gulf Stream, the interior of the North Pacific, and the Southern Ocean (see the green rectangular boxes in Figure 1), and (B) the Northern Hemisphere (NH), the Southern Hemisphere (SH), and the global ocean. 
the annual cycles of EKE averaged over the $\mathrm{NH}$ and $\mathrm{SH}$ are of similar magnitude but in opposite phase to each other, the globally-averaged EKE shows little seasonal variability.

\subsection{Eddy Momentum Flux}

The global eddy momentum flux averaged over our study period, $\overline{u^{\prime} v^{\prime}}$, reveals a number of organised patterns with alternating signs (Figure 4). Large values of $\overline{u^{\prime} v^{\prime}}$ are concentrated mostly in the western boundary currents regions and in the Southern Ocean. In the South Indian and South Pacific Oceans, there are wide-spread negative $\overline{u^{\prime} v^{\prime}}$ equatorward of $\sim 24^{\circ} \mathrm{S}$ and a narrow band of positive $\overline{u^{\prime} v^{\prime}}$ immediately poleward of that latitude. A band of positive $\overline{u^{\prime} v^{\prime}}$ is found to the east of the Hawaii Islands, extending all the way to the western boundary, suggesting a far-reaching effect of these island chains in shaping eddy momentum flux in the North Pacific. Near the continental slopes, a striking feature emerges: $\overline{u^{\prime} v^{\prime}}$ is ubiquitously positive where the continental slope is orientated in the southwest/northeast direction and is ubiquitously negative where the continental slope is orientated in the southeast/northwest direction. As noted by Greatbatch et al. (2010a), the steep continental slope encourages not only the mean flow but also flow variability to be predominantly in the along-slope direction (see Morrow et al. (1994) and Scott et al. (2008) for evidence of the alignment of surface current variance ellipses with steep topography). As such, $u^{\prime}$ and $v^{\prime}$ tend to be positively correlated when the continental slope is orientated in the southwest/northeast direction, producing positive $\overline{u^{\prime} v^{\prime}}$. The opposite is true when the continental slope is orientated in the southeast/northwest direction.

We now focus on $\overline{u^{\prime} v^{\prime}}$ and its seasonal variations in the Kuroshio and Gulf Stream regions. In the case of the Gulf Stream, there are two prominent features: a double-blade shaped positive $\overline{u^{\prime} v^{\prime}}$ immediately following the separation of the Gulf Stream from the coast near Cape Hatteras and a patch of negative $\overline{u^{\prime} v^{\prime}}$ to the south of the Grand Banks of Newfoundland (Figure 5). Both features were also noted in Ducet and Le Traon (2001) and Greatbatch et al. (2010a) where fewer years (5 and 12 years respectively) of altimeter data were used to estimate surface eddy momentum fluxes. The robustness of these features is therefore demonstrated by their occurrence regardless of the analysis periods used in the present and previous studies. Both features can be explained by preferred flow variability along the direction of the mean flow (northeastward near Cape Hatteras and southeastward south of the Grand Banks), due most likely to the constraint of the neighboring continental slope (Greatbatch et al., 2010a). On the other hand, the longer averaging period used in this study does bring out a clearer picture of $\overline{u^{\prime} v^{\prime}}$ in the region between the New England Seamounts and the Grand Banks. Negative values of $\overline{u^{\prime} v^{\prime}}$ are generally found on the northern flank of the Gulf Stream and positive values on the southern flank (Figure 5b), supporting the idea that horizontal momentum fluxes by the eddies act to strengthen the Gulf Stream jet. To get rid of the smallscale features in Figure 5, we zonally average $\overline{u^{\prime} v^{\prime}}$ over the Gulf Stream region (bold black line in Figure 6a). It becomes clear that the eddies systematically extract westerly momentum from both sides of the Gulf Stream and flux it into the Gulf Stream jet in the latitude band between $37^{\circ} \mathrm{N}$ and $41^{\circ} \mathrm{N}$. In doing so, the eddy momentum flux, $\overline{u^{\prime} v^{\prime}}$, contributes to driving both the northern and southern recirculation gyres of the Gulf Stream (Greatbatch et al., 2010b).

The overall patterns of $\overline{u^{\prime} v^{\prime}}$ in both winter and summer are very similar to that of the annual mean, although

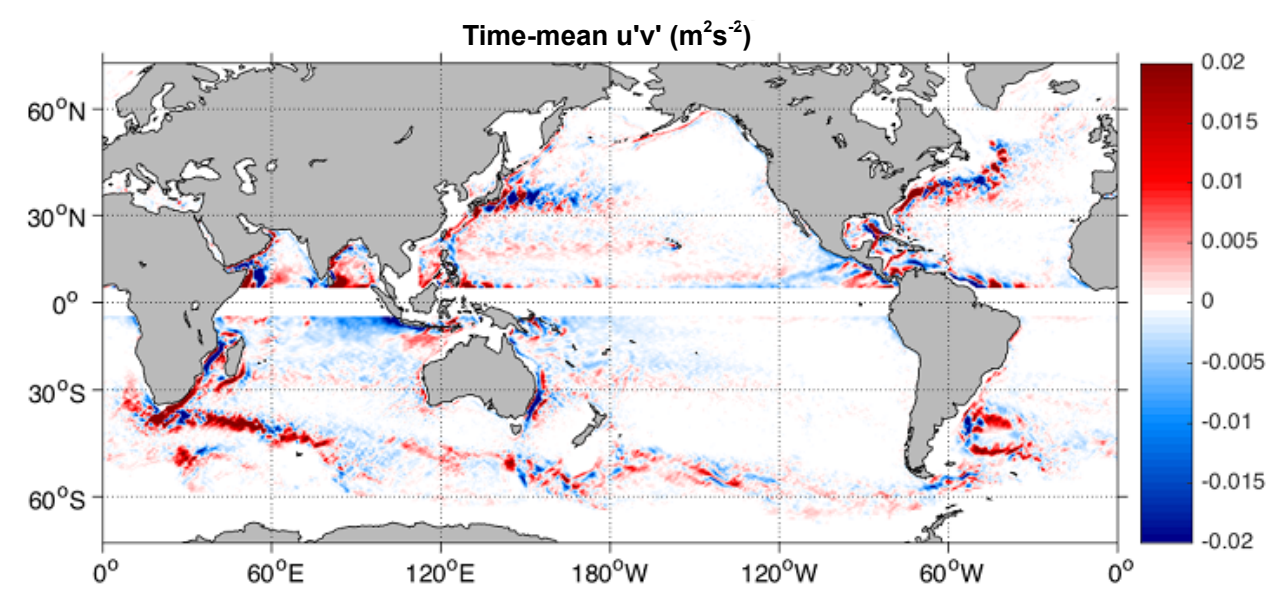

Figure 4. Time-mean $\overline{u^{\prime} v^{\prime}}$ over the period of 1993-2016. 
(A) Time-mean u'v' $\left(\mathrm{m}^{2} \mathrm{~s}^{-2}\right)$ with bathymetry contours

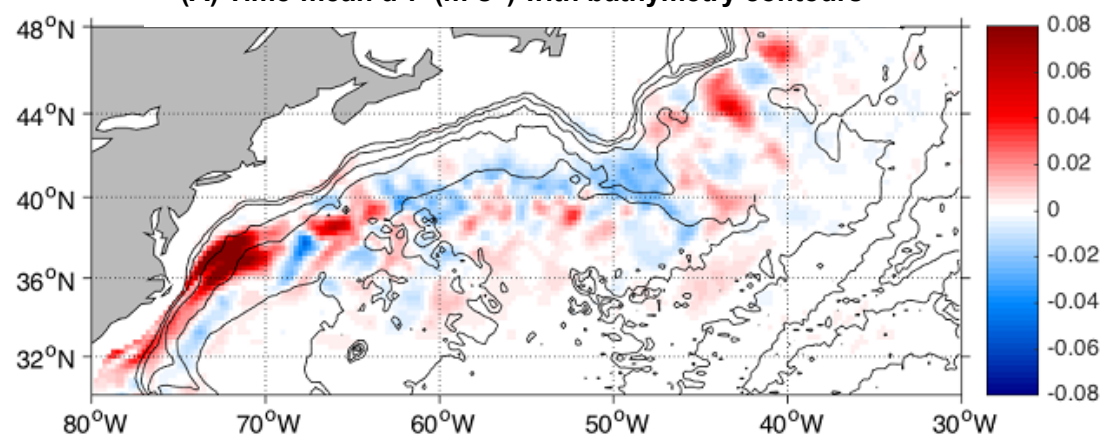

(B) Time-mean u'v' $\left(\mathrm{m}^{2} \mathbf{s}^{-2}\right)$ with mean sea surface height contours

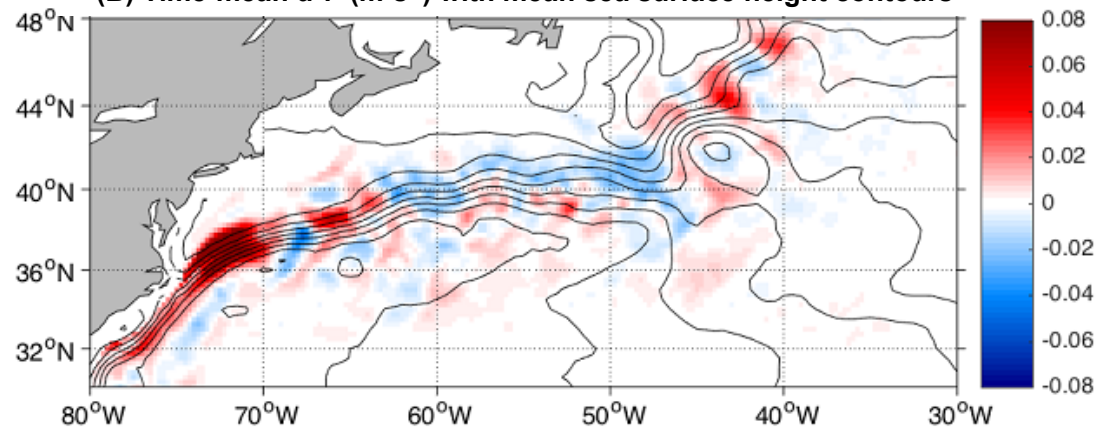

Figure 5. Time-mean $\overline{u^{\prime} v^{\prime}}$ in the Gulf Stream region overlaid (A) with bathymetry contours with contour interval of $1000 \mathrm{~m}$ and (B) with the mean sea surface height contours from Niiler et al. (2003) with contour interval of $0.1 \mathrm{~m}$. Note the different colour scale from that used in Figure 4.

(A)

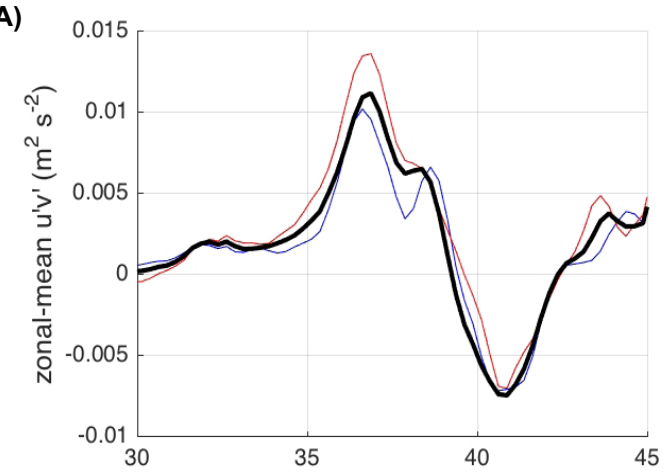

(B)

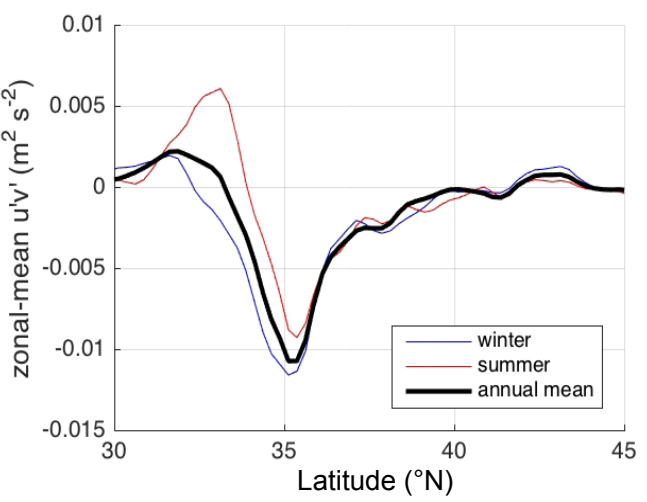

Figure 6. Zonal-mean $\overline{u^{\prime} v^{\prime}}$ in (A) the Gulf Stream region and (B) the Kuroshio Extension region. the double-blade feature near Cape Hatteras becomes more pronounced in summer (Figure 7). As a result, after zonal averaging, the peak value of $\overline{u^{\prime} v^{\prime}}$ at $37^{\circ} \mathrm{N}$ is about one-third greater in summer than in winter, and the convergence of westerly momentum flux into the zonalmean zonal flow between $37^{\circ} \mathrm{N}$ and $41^{\circ} \mathrm{N}$ is about $18 \%$ greater in summer than in winter (Figure 6a). The result that large eddy momentum flux and flux convergence are found in summer is consistent with the annual cycle of EKE in this region, which also peaks in the summer season. We argue that these seasonal variations of $\overline{u^{\prime} v^{\prime}}$, being sizable in magnitude, may play an important role in modulating the strength of the Gulf Stream and its recirculation gyres on the seasonal time scale.

In the Kuroshio Extension region, there is an array of $\overline{u^{\prime} v^{\prime}}$ patches of alternating signs between Japan and $155^{\circ} \mathrm{E}$ (Figure 8 ), broadly similar to those found in Ducet and Le Traon (2001) and Greatbatch et al. (2010a), again demonstrating the robustness of these features. The juxtaposition of $\overline{u^{\prime} v^{\prime}}$ patches and the mean flow meanders shows that there is preferred flow variability along the direction of the mean flow meander. Indeed, positive patches of $\overline{u^{\prime} v^{\prime}}$ are found in the Kuroshio meander where the mean flow is northeastward, and negative patches where the mean flow is southeastward (Figure 8b). In Greatbatch et al. (2010a), $\overline{u^{\prime} v^{\prime}}$ after zonal integrating, was 


\section{(A) Winter-mean u'v' $\left(\mathrm{m}^{2} \mathrm{~s}^{-2}\right)$}

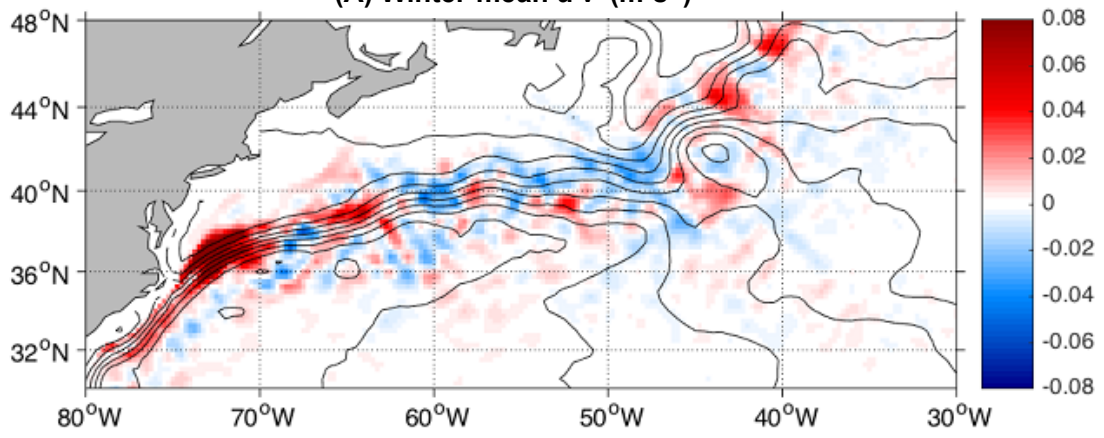

(B) Summer-mean $u^{\prime} v^{\prime}\left(m^{2} s^{-2}\right)$

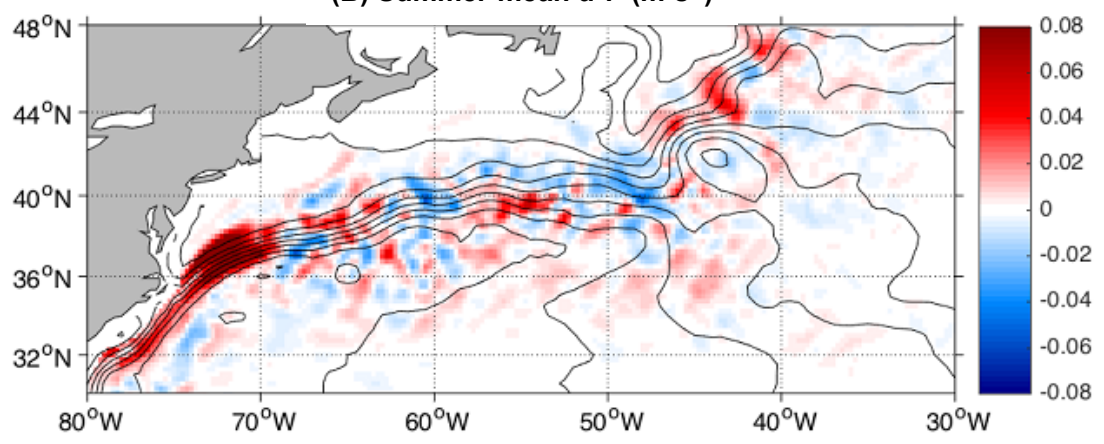

Figure 7. (A) Winter-mean and (B) summer-mean $\overline{u^{\prime} v^{\prime}}$ in the Gulf Stream region overlaid with the mean sea surface height contours from Niiler et al. (2003) with contour interval of $0.1 \mathrm{~m}$.

(A) Time-mean u'v' $\left(\mathrm{m}^{2} \mathrm{~s}^{-2}\right)$ with bathymetry contours

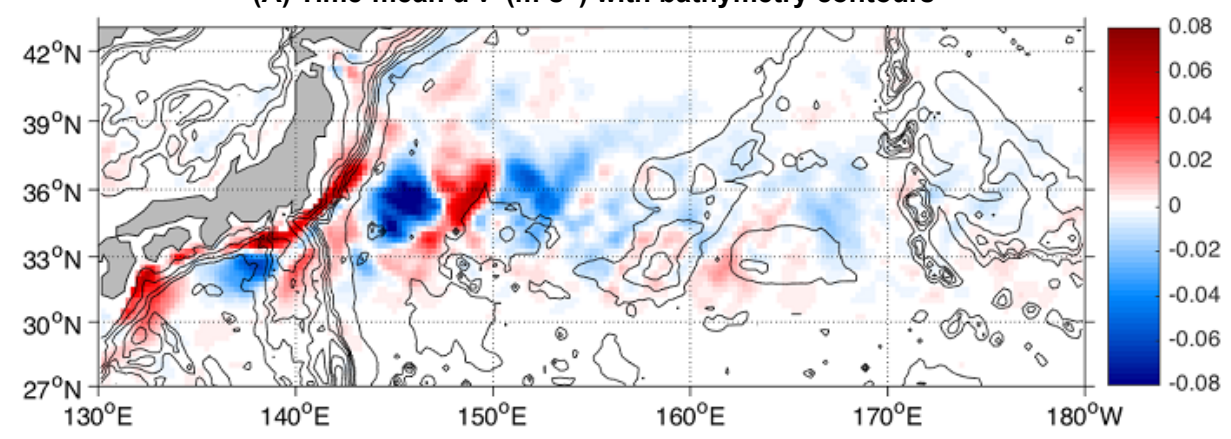

(B) Time-mean $u^{\prime} v^{\prime}\left(m^{2} s^{-2}\right)$ with mean sea surface height contours

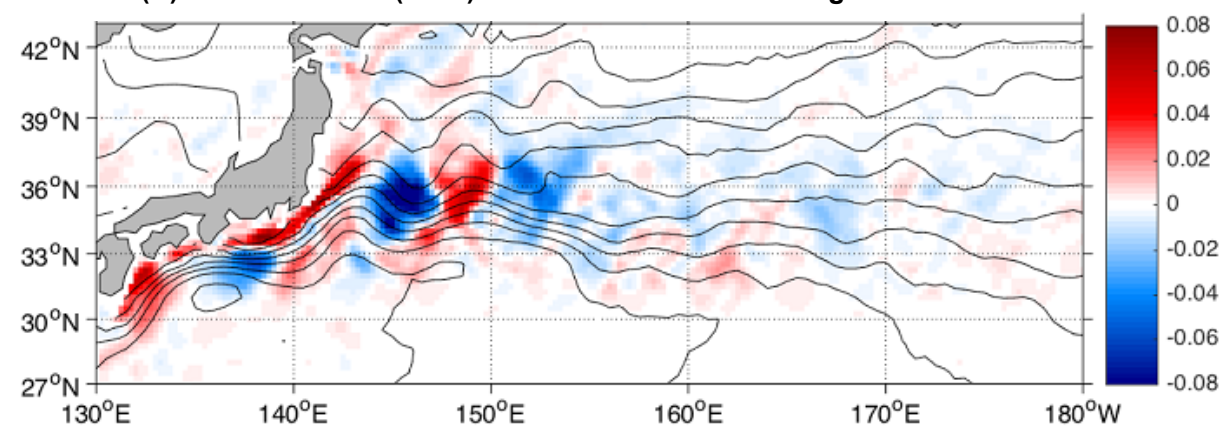

Figure 8. Time-mean $\overline{u^{\prime} v^{\prime}}$ in the Kuroshio Extension region overlaid (A) with bathymetry contours with contour interval of $1000 \mathrm{~m}$ and (B) with the mean sea surface height contours from Niiler et al. (2003) with contour interval of $0.1 \mathrm{~m}$. 
found to change sign several times between $30^{\circ} \mathrm{N}$ and $40^{\circ} \mathrm{N}$, implying that eddy momentum flux feeds/extracts westerly momentum into/out of alternating latitude bands, although no such bands of zonal mean flow were found in the Niiler et al. (2003) mean sea surface height product. With the longer record of altimeter data that has now become available, a clearer and simpler picture emerges after zonal averaging (bold black line in Figure 6b): the eddies systematically extract westerly momentum from regions to the south and north of the Kuroshio Current and deposit it in the latitude band between $32^{\circ} \mathrm{N}$ and $35.5^{\circ} \mathrm{N}$ where the strongest zonalmean zonal flow is situated (see Figure 7 in Greatbatch et al. (2010a)). We therefore conclude that, at least in the zonal-mean sense, eddy momentum fluxes in the Gulf Stream and Kuroshio Extensions are not that dissimilar: they both act to strengthen the western boundary current and drive the recirculation gyres to the north and south (Qiu et al., 2008; Greatbatch et al., 2010b).

The seasonal variations of $\overline{u^{\prime} v^{\prime}}$ are more pronounced in the Kuroshio Extension region: both the middle negative and positive patches of $\overline{u^{\prime} v^{\prime}}$ become visibly more enhanced in summer (Figure 9). Figure 6b shows that the positive peak of the zonal-mean $\overline{u^{\prime} v^{\prime}}$ is over twice greater in summer than in winter (and also shifts slightly northward in summer), while the negative peak at $35.5^{\circ} \mathrm{N}$ is $\sim 25 \%$ greater in winter than in summer. Consequently, the convergence of westerly momentum flux into the latitudes between the maximum and minimum zonalmean $\overline{u^{\prime} v^{\prime}}$ is $\sim 13 \%$ greater in summer than in winter. We therefore expect a stronger eddy-driven northern recirculation gyre in winter and a much stronger eddydriven southern recirculation gyre in summer in the Kuroshio Extension region.

\section{Summary}

In this study, we have investigated the annual cycle of surface EKE and its influence on eddy momentum flux using an updated record of satellite altimeter data. Our main findings are:

- EKE in the western boundary current regions and EKE in the interior of the subtropical gyres peak in summer and late spring, respectively. The phase difference between them suggests that different mechanisms may be at work in maintaining the annual cycles of EKE in different parts of the subtropical gyres.

- The annual cycles of EKE averaged over the NH and $\mathrm{SH}$ are of similar magnitude but in opposite phase to each other, both reaching their seasonal maximums in respective hemispheric summers. As a result, the globally-averaged EKE shows little

(A) Winter-mean u'v' $\left(\mathrm{m}^{2} \mathrm{~s}^{-2}\right)$

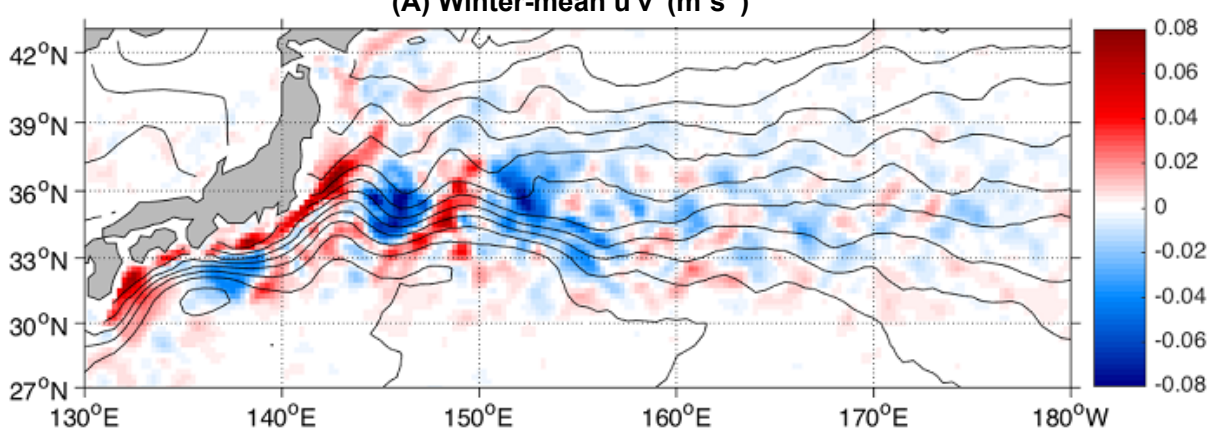

(B) Summer-mean u'v' $\left(m^{2} s^{-2}\right)$

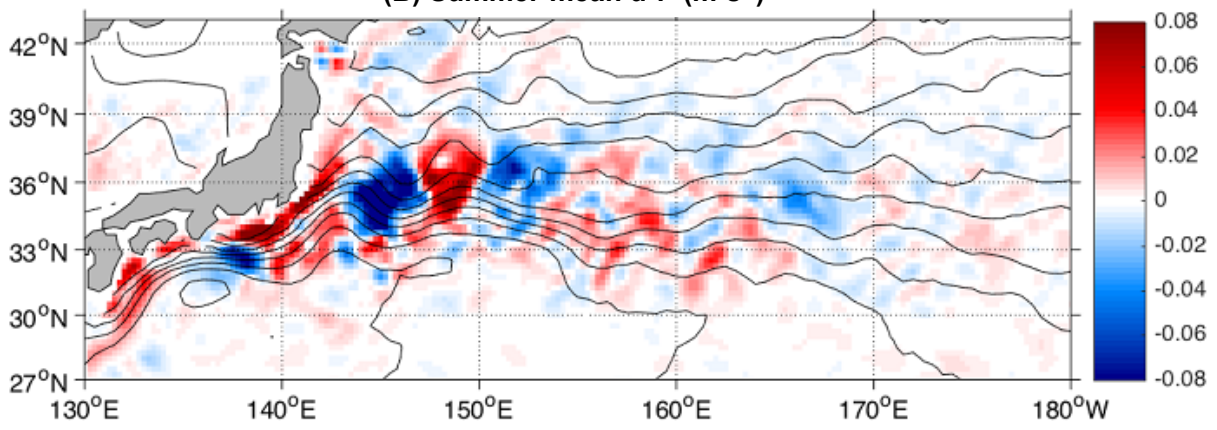

Figure 9. (A) Winter-mean and (B) summer-mean $\overline{u^{\prime} v^{\prime}}$ in the Kuroshio Extension region overlaid with the mean sea surface height contours from Niiler et al. (2003) with contour interval of $0.1 \mathrm{~m}$. 
seasonal variability.

- Thanks to the longer record of altimeter data that has now become available, clearer and simpler pictures of eddy momentum flux in the Gulf Stream and Kuroshio Extension emerge. Between the New England Seamounts and the Grand Banks of Newfoundland, negative values of $\overline{u^{\prime} v^{\prime}}$ are generally found to the north of the Gulf stream and positive values to the south, supporting the idea that eddies systematically flux westerly momentum into the Gulf Stream jet. The zonal-mean structure of $\overline{u^{\prime} v^{\prime}}$ in the Kuroshio Extension is found to be similar to that in the Gulf Stream, in contrast with the findings in the earlier studies where fewer years of altimeter data were used.

- Our results show that the annual cycle of surface EKE does have dynamical consequences for eddymean flow interactions. Large eddy momentum flux and flux convergence are found in the western boundary current regions in the summer season when surface EKE reaches its maximum. We argue that the seasonal variations of $\overline{u^{\prime} v^{\prime}}$ are sizable in magnitude and may play an important role in modulating the strength of the western boundary currents and their associated recirculation gyres on the seasonal time scale.

\section{Conflict of Interest}

No conflict of interest was reported by the authors.

\section{Acknowledgements}

I wish to thank Richard Greatbatch and Jan Rieck for helpful discussions and two anonymous reviewers for their constructive comments. The Ssalto/Duacs altimeter products were produced and distributed by the Copernicus Marine and Environment Monitoring Service (CMEMS) (http://www.marine.copernicus.eu).

\section{References}

Ducet N and Le Traon P-Y. (2001). A comparison of surface eddy kinetic energy and Reynolds stresses in the Gulf Stream and the Kuroshio Current systems from merged TOPEX/ Poseidon and ERS-1/2 altimetric data. Journal of Geophysical Research: Ocean, 106(C8): 16603-16622.

http://dx.doi.org/10.1029/2000JC000205

Duhaut T H A and Straub D N. (2006). Wind stress dependence on ocean surface velocity: Implications for mechanical energy input to ocean circulation. Journal of Physical Oceanography, 36: 202-211.

http://dx.doi.org/10.1175/JPO2842.1

Eady E T. (1949). Long waves and cyclone waves. Tellus, 1(3):
33-52.

http://dx.doi.org/10.1111/j.2153-3490.1949.tb01265.x

Greatbatch R J, Zhai X, Kohlmann J-D, et al. (2010a). Ocean eddy momentum fluxes at the latitudes of the Gulf Stream and the Kuroshio extensions as revealed by satellite data. Ocean Dynamics, 60(3): 617-628.

http://dx.doi.org/10.1007/s10236-010-0282-6

Greatbatch R J, Zhai X, Claus M, et al. (2010b). Transport driven by eddy momentum fluxes in the Gulf Stream Extension region. Geophysical Research Letters, 37(24): L24401.

http://dx.doi.org/10.1029/2010GL045473

Hecht M W and Smith R D. (2008). Towards a physical understanding of the North Atlantic: A review of model studies in an eddying regime. In: Hecht $\mathrm{M} \mathrm{W}$ and Hasumi H (editors). Ocean modelling in an eddying regime. Washington: American Geophysical Union, p.213-240.

http://dx.doi.org/10.1029/GM177

Morrow R A, Coleman R, Church J, et al. (1994). Surface eddy momentum flux and velocity variances in the Southern Ocean from GEOSAT altimetry. Journal of Physical Oceanography, 24: 2050-2071.

http://dx.doi.org/10.1175/1520-0485(1994)024<2050:SEMFA $\mathrm{V}>2.0 . \mathrm{CO} ; 2$

Niiler P P, Maximenko N A and McWilliams J C. (2003). Dynamically balanced absolute sea level of the global ocean derived from near-surface velocity observations. Geophysical Research Letters, 30(22): 2164.

http://dx.doi.org/10.1029/2003GL018628

Penduff T, Barnier B, Dewar W K, et al. (2004). Dynamical responses of the oceanic eddy field to the North Atlantic Oscillation: A model-data comparison. Journal of Physical Oceanography, 34: 2615-2629.

http://dx.doi.org/10.1175/JPO2618.1

Qiu B. (1999). Seasonal eddy field modulation of the North Pacific Subtropical Countercurrent: TOPEX/Poseidon observations and theory. Journal of Physical Oceanography, 29: 24712486.

http://dx.doi.org/10.1175/1520-0485(1999)029<2471:SEFMO $\mathrm{T}>2.0 . \mathrm{CO} ; 2$

Qiu B, Chen S, Hacker P, et al. (2008). The Kuroshio Extension northern recirculation gyre: Profiling float measurements and forcing mechanism. Journal of Physical Oceanography, 38: 1764-1779.

http://dx.doi.org/10.1175/2008JPO3921.1

Rieck J K, Böning C W, Greatbatch R J, et al. (2015). Seasonal variability of eddy kinetic energy in a global high-resolution 
ocean model. Geophysical Research Letters, 42(21): 93799386.

http://dx.doi.org/10.1002/2015GL066152

Scott R B, Arbic B K, Holland C L, et al. (2008). Zonal versus meridional velocity variance in satellite observations and realistic and idealised ocean circulation models. Ocean Modelling, 23(3-4): 102-112.

http://dx.doi.org/10.1016/j.ocemod.2008.04.009

Stammer D and Wunsch C. (1999). Temporal changes in eddy energy of the ocean. Deep-Sea Research, 46(1-2): 77-108. http://dx.doi.org/10.1016/S0967-0645(98)00106-4

Wilson C, Hughes C, and Blundell J R. (2015). Forced and intrinsic variability in the response to increased wind stress of an idealised Southern Ocean. Journal of Geophysical Research, 120(1): 113-130. http://dx.doi.org/10.1002/2014JC010315

Xu C, Zhai X and Shang X D. (2016). Work done by atmospheric winds on mesoscale ocean eddies. Geophysical Research Letters, 43(23): 12,174-12,180. http://dx.doi.org/10.1002/2016GL071275

Zhai X and Greatbatch R J. (2006a). Surface eddy diffusivity for heat in a model of the northwest Atlantic Ocean. Geophysical
Research Letters, 33(24): L24611.

http://dx.doi.org/10.1029/2006GL028712

Zhai X and Greatbatch R J. (2006b). Inferring eddy-induced diffusivity for heat in the surface mixed layer using satellite data. Geophysical Research Letters, 33(24): L24607. http://dx.doi.org/10.1029/2006GL027875

Zhai X and Greatbatch R J. (2007). Wind work in a model of the northwest Atlantic Ocean. Geophysical Research Letters, 34(4): L04606.

http://dx.doi.org/10.1029/2006GL028907

Zhai X and Wunsch C. (2013). On the variability of wind power input to the oceans with a focus on the subpolar North Atlantic. Journal of Climate, 26: 3892-3903. http://dx.doi.org/10.1175/JCLI-D-12-00472.1

Zhai X, Greatbatch R J and Sheng J. (2004). Diagnosing the role of eddies in driving the circulation of the northwest Atlantic Ocean. Geophysical Research Letters, 31(23): L23304. http://dx.doi.org/10.1029/2004GL021146

Zhai X, Greatbatch R J and Kohlmann J-D. (2008). On the seasonal variability of eddy kinetic energy in the Gulf Stream region. Geophysical Research Letters, 35(24): L24609. http://dx.doi.org/10.1029/2008GL036412 